\title{
Private versus public old-age security
}

Richard C. Barnett, Joydeep Bhattacharya, Mikko Puhakka

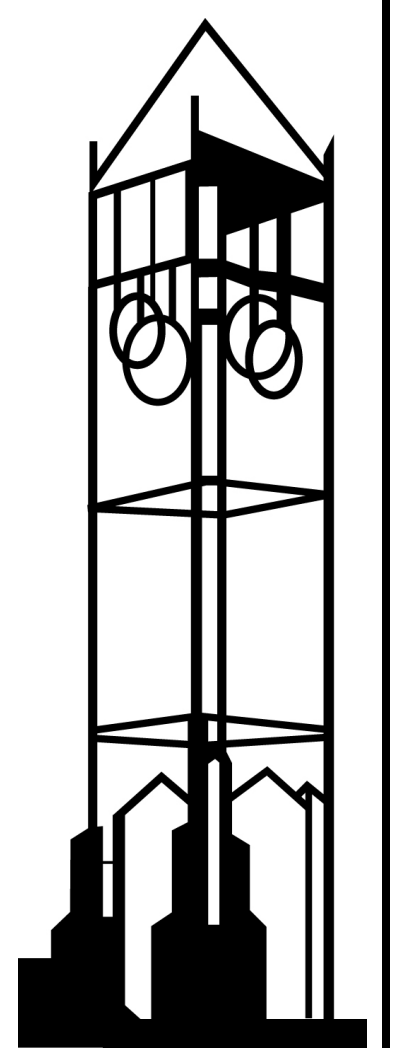

Working Paper No. 12016

September 2012

\section{IOWA STATE UNIVERSITY}

Department of Economics

Ames, lowa, 50011-1070

lowa State University does not discriminate on the basis of race, color, age, religion, national origin, sexual orientation, gender identity, genetic information, sex, marital status, disability, or status as a U.S. veteran. Inquiries can be directed to the Director of Equal Opportunity and Compliance, 3280 Beardshear Hall, (515) 294-7612. 


\title{
PRIVATE VERSUS PUBLIC OLD-AGE SECURITY
}

\author{
Richard C. Barnett \\ Drexel University
}

\author{
Joydeep Bhattacharya \\ Iowa State University
}

September 2, 2012

\author{
Mikko Puhakka* \\ University of Oulu
}

\begin{abstract}
We compare two institutions head on, a family compact - a parent makes a transfer to her parent in anticipation of a possible future gift from her children - with a pay-as-you-go, social security system in a lifecycle model with endogenous fertility wherein children are valued both as consumption and investment goods. Our focus is strictly on the pension dimension of these competing institutions. We show that an optimally-chosen family compact and a social security system cannot co-exist; indeed, the former may be preferred. A strong-enough negative shock to middle-age incomes destroys family compacts. While such a setting might appear ideal for the introduction of a social security system - as the experience of Europe, circa 1880s, would suggest - this turns out not to be the case: if incomes are too depressed to allow family compacts to flourish, they are also too low to permit introduction of an optimal social security system.
\end{abstract}

Keywords: fertility, family compacts, social security, intergenerational cooperation, pensions, self-enforcing constitutions

JEL Classifications: E 21, E 32

*Puhakka thanks the Yrjö Jahnsson Foundation and the OKO Bank Foundation for support. 
"I've always said, and I still think we have to admit, that no matter how much fine reasoning there was about the old-age insurance system and the unemployment insurance prospects-no matter how many people were studying it, or how many committees had ideas on the subject, or how many college professors had written theses on the subject-and there were an awful lot of them-the real roots of the Social Security Act were in the Great Depression of 1929. Nothing else would have bumped the American people into a social security system except something so shocking, so terrifying, as that depression.” (Frances Perkins, U.S. Secretary of Labor, 1962).

\section{Introduction}

For centuries, before the advent of compulsory, tax-funded social security, financial sustenance of the elderly relied on two sources: their own savings and/or family support. The latter was facilitated by working-age children under an implicit family compact - each young generation pledged to support their parents, just as their parents had supported their grandparents in the past. Within family lines, these compacts worked for many generations and helped prevent the immiserization of large segments of the elderly population. By early 1900s, industrialization had become widespread in Europe; with it, business cycles increased in frequency, ferocity, and length. Economy-wide unemployment and long episodes of depressed wages became routine. These eroded the by-now meager savings of many elderly and often precipitated the destruction of the aforementioned family compacts.

In the late 19th century, northern Europe attempted to confront the growing problem of economic deprivation and old-age dependency by developing a radically new social ideology - an ideology that challenged a three-century old Poor Law system ${ }^{1}$ and instead, entrusted government with responsibility for the aging members of society. Following a long period of economic depression in the middle of the second half of the century, Bismarck's Germany ushered in landmark

\footnotetext{
1 "The English Poor Law of 1601 was the first systematic codification of English ideas about the responsibility of the state to provide for the welfare of its citizens. It provided for taxation to fund relief activities; it distinguished between the "deserving" and the "undeserving" poor; relief was local and community controlled; and almshouses were eventually established to house those on relief. The law was at once both generous and harsh. Generous in that it acknowledged the government's duty to provide for the welfare of the poor, but harsh in that it viewed the poor as highly undesirable characters and treated them accordingly." http://www.ssa.gov/history/briefhistory3.html
} 
socio-economic reforms ensuring state protection for workers in the areas of health (1883) and old age (1891). ${ }^{2}$ The social insurance system that emerged, quickly spread to the rest of Europe. Denmark, Norway and England were among the early adopters; eventually by 1930 or so, it had spread to America.

This paper formalizes some of these ideas within a stylized model of intergenerational transfers inspired by Cigno (2006a,b). A key feature of the Cigno framework we adopt is the absence of intergenerational altruism as motivation for intergenerational solidarity. We study a simple, threeperiod overlapping generations model with endogenous fertility in which the decision makers are middle-aged agents who value children both as consumption and investment goods. The latter role arises because children provide the means of a family pension system, a family compact, in which the parent, when young, passes along a transfer to her parent in anticipation of receiving a possible transfer from each of her children in the future. We derive, in a stationary setting, the optimal family compact, one that is sub-game perfect because it dominates the outside option of generational autarky.

As a competitor, we introduce a simple, pay-as-you-go pension system or social security (henceforth "SS"), one that taxes the income of the middle-aged and uses the proceeds to make lump-sum transfers to the old. Our focus here is strictly on the pension role of a social security plan. We show that a benevolent government has no welfare justification for introducing SS in a world with actively-thriving family compacts; i.e., both a private family compact and a public SS system cannot co-exist. Put differently, a public SS system cannot improve upon the lives of people under optimally-chosen private family compacts. The problem lies in the fact that private agents view the public tax-transfer scheme as lump sum; they do not internalize the budgetary implications

\footnotetext{
${ }^{2}$ In Bismarck's own words: "The workers' real complaint results from the insecurity of their livelihood; they cannot be certain that they will always be employed; they cannot be certain that they will always enjoy good health and they know that one day they will be old and unable to work . . . and society does not really recognize any obligation towards them apart from the common Poor Law provisions, however loyally and industrially any particular worker may have worked in the past. . . . These classes must through direct and noticeable advantages bestowed upon them by legislation be brought to look upon the State as not merely an institution invented for the protection of the more well-to-do classes of society, but one that also serves their interests and needs by securing them direct and tangible advantages through legislative measures . ." Also see Atchley (1982).
} 
of their fertility decision (which the government takes as given) meaning they fail to understand the connection between the pension they are promised and the number of kids they have. ${ }^{3}$ Since agents ignore this budgetary margin, the government's ability to influence agents' welfare via its tax-transfer policies is hampered.

We go on to show that family compacts may self-destruct if the income of the middle-aged takes a big, permanent hit. That is, a sufficient condition for family compacts to break down (and be replaced by generational autarky) is a large-enough, negative shock to middle-age incomes. Common intuition suggests such a setting is ripe for the introduction of SS, as indicated by the aforediscussed experience of Europe, circa 1880s. ${ }^{4}$ Interestingly, this turns out not to be the case. We show, and this is our flagship result, that if incomes are too depressed to allow family compacts to thrive, they are also too low to permit introduction of an optimal SS system.

Does this mean SS systems are redundant? Consider a thought experiment in which family compacts could flourish but are disallowed, say by law, resulting in a situation of involuntary generational autarky. In that setting, stationary welfare would be higher if a SS system of the type we have discussed is introduced. However, if family compacts are allowed to exist and if indeed they flourish, there is no point introducing SS as a competitor. And if family compacts don't exist on their own, then in those settings, there is again no benefit to introducing a SS system. It bears emphasis here that our work only suggests SS systems are redundant because they serve no efficiency-enhancing, pension role over and beyond the family compacts. In other words, it is our contention that the justification for introducing SS, in a world with robust family compacts, must lie outside of its pension role. ${ }^{5}$

\footnotetext{
${ }^{3}$ If private agents did internalize the budgetary implications of the public scheme, their fertility decision and the accompanying pension would exactly match what obtains under the compact.

${ }^{4}$ See Tanzi and Schuknecht (2000) for data on year-of-introduction for voluntary and compulsory pension insurance in European countries.

5 "So, also, security was attained in the earlier days through the interdependence of members of families upon each other and of the families within a small community upon each other. The complexities of great communities and of organized industry make less real these simple means of security. Therefore, we are compelled to employ the active interest of the Nation as a whole through government in order to encourage a greater security for each individual who composes it." FDR's "Message To Congress Reviewing The Broad Objectives And Accomplishments Of The Administration", JUNE 8, 1934. http://www.ssa.gov/history/fdrstmts.html\#message1
} 
Private family compacts and public SS systems, stripped of all adornments, are vehicles of intergenerational transfers, one via the family line and one intermediated by the government. And yet, the entire literature on SS systems and their raison d'être - surveyed, for example, in Mulligan and Sala-i-Martin (2004) - focuses on their efficiency and redistributive properties in isolation, but never in a direct, head-on comparison with private family compacts. Therein, lies the value added of our work. Our work does not attempt to add to the, by now, vast literature exploring the connections between SS, fertility and development. Much of that literature focuses on explaining why SS blunts parental incentives to have children, a feature present in our model but not our primary concern. ${ }^{6}$ Our work, naturally, borrows from the literature on within-family transfers unmotivated by altruism, emanating from Cigno (1993), and enhanced in Rosati (1996), and Cigno $(2006 a, b){ }^{7}$

We proceed as follows. In Section 2, we describe the model environment, population structure, the behavior of economic agents and the stationary private family compacts. In Section 3, we characterize the public social security system and compare it to the private family compact. The appendix contains the fine print of the family compacts as well as a fully worked-out example with logarithmic utility.

\footnotetext{
${ }^{6}$ Nishimura and Zhang (1992), Ehrlich and Lui (1998) and Zhang and Zhang (1995) contend that public social security systems distort fertility and explore this idea in models with altruistic agents. The same conclusion is reached by Ehrlich and Kim (2005). Boldrin, De Nardi, and Jones (2005) demonstrate the effect of old-age pensions in fertility in two types of calibrated models. In a model based on Boldrin and Jones (2002) they show that the effect is quite large, but in an altruistic model based on Barro and Becker (1989) it is actually very small.

${ }^{7}$ Our paper is also related to the influential paper by Zhang and Zhang (1998) wherein children are investment goods and transfer an endogenously-determined fraction of their income to their old parents. In their setup, social security is not welfare neutral; it increases economic growth and welfare by reducing fertility. Hence, social security is a more efficient means of consumption smoothing over the life cycle than are children. They, however, do not study optimal family compacts in the tradition of Cigno (1993); nor is the head-on comparison of both institutions their concern. In a recent paper, Galasso and Profeta (2010) analyze the link between the structure of family - whether characterized by weak or strong family ties - and the emergence of pension systems. In their "new regime", one characterized by industrialization, urbanization and nuclear families, weak family ties are conducive to the rise of public pension systems, yet, if they emerge, pension systems are more generous in societies with strong family ties.
} 


\section{The Basic Model}

Consider an economy populated by cohorts of three-period lived overlapping generations that are economically active for the last two periods of life. Label the periods of life as childhood, youth, and old-age with childhood being economically passive. Let $t=1,2, \ldots, \infty$ denote time.

A young decision-maker (one born at date $t-1$ ) at any date is endowed with $w>0$ units of a single, non-storable consumption good; she is endowed with $y \geq 0$ units of the same good when old. When young, she decides how many children, $n_{t}$, to raise at a contemporaneous cost of $v$ per child. $^{8}$

To simplify the analysis, we assume there are no financial assets. ${ }^{9}$ Children, potentially, serve two purposes in this economy. First, following the tradition of Becker and Barro (1988), Galor and Weil (1996) and many others, the number of children provide direct utility to the parent. Second, following the tradition of Cigno (1993), offspring may be considered akin to investment goods insofar as they provide the means of a family pension system in which the parent, when young, passes along a transfer $\alpha_{t}>0$ of goods to her parent in anticipation of receiving a possible transfer $\alpha_{t+1}>0$ from each of her children in the future.

A sequence $\left\{\alpha_{t}\right\}_{t=1}^{\infty}$ represents a family pension system, or family constitution (Cigno, 1993) or family compact (FC, hereafter), discussed in detail below. Let $\underline{U}_{t}$ (defined in the section below) denote the agent's benchmark utility, i.e., what she can achieve on her own without participating in the FC. Within a FC, however, a young agent at $t$ faces a family-transfer obligation to transfer $\alpha_{t}$ units of the good to her parents, with the understanding that she receives filial support from each of her children - they will transfer $\alpha_{t+1}$ units of the good to her (a total transfer of $\alpha_{t+1} n_{t}$ ) at date

\footnotetext{
${ }^{8}$ The total number of people at each date $t$ is $N_{t}=N_{t}^{c}+N_{t}^{y}+N_{t}^{o}$ where $N_{t}^{i}$ is the size of the cohort $i$ of the same age at date $t$. Since $N_{t}=\left(1+n_{t} n_{t-1}+n_{t-1}\right) N_{t}^{o}$ and $N_{t+1}=\left(1+n_{t} n_{t+1}+n_{t}\right) N_{t+1}^{o}=\left(1+n_{t} n_{t+1}+n_{t}\right) n_{t-1} N_{t}^{o}$, the gross population growth rate is $\frac{N_{t+1}}{N_{t}}=\frac{\left(1+n_{t} n_{t+1}+n_{t}\right) n_{t-1}}{\left(1+n_{t} n_{t-1}+n_{t-1}\right)}$. In the steady state (or on a balanced growth path), $N_{t+1} / N_{t}=n$.

${ }^{9}$ If private saving was allowed, a lack of return dominance property - the saving instrument and the FC had to yield the same rate of return - would obtain and this would influence the autarkic option. A consequence of disallowing a private saving option is that fully-funded pension systems can no longer be studied within the confines of our setup. That lacuna is not of great significance because, historically speaking, fully funded systems appeared long after family compacts had been destroyed and pay-as-you-go pension systems were firmly in vogue. Cigno (2006 a) introduces a savings instrument because of his interest in the effect of pensions on lifecycle saving.
} 
$t+1$. Of course, the agent can choose to abide by the obligation or not; if she agrees to, she is, in the language of Cigno (2006a), a "complier", otherwise, she is a "go-it-aloner". A FC is, then, an entire sequence of such family-transfer obligations, one for each date. Clearly, for a FC to be operative, it is necessary that each generation attains at least $\underline{U}_{t}$ in utility under it.

The lifetime utility of a young decisionmaker at date $t$ is

$$
u\left(c_{t}\right)+\beta u\left(x_{t}\right)+\theta g\left(n_{t}\right)
$$

where $c_{t}\left(x_{t}\right)$ is the agent's consumption when young (old), and $0<\beta \leq 1$ and $\theta \geq 0$ are preference parameters. The functions $u(\cdot)$ and $g(\cdot)$ are increasing and concave; they also satisfy $u^{\prime}(0)=\infty$, and $g^{\prime}(0)=M \leq \infty$. It is important to note that the aforediscussed intergenerational transfers are not based on altruism, since a parent's well-being is not an argument of the young agent's utility function. ${ }^{10}$

At points below, we will consider a competing, publicly-funded pension system. Let $\left(\tau_{t}, b_{t-1}\right)$ summarize a pay-as-you-go public pension system (social security, hereafter SS), where $\tau_{t}$ is a lump-sum tax collected at date $t$ from a young agent and $b_{t-1}$ is a contemporaneous transfer to each old agent. Assuming the government balances its budget at each date, a sequence $\left\{\tau_{t}, b_{t-1}\right\}_{t=1}^{\infty}$ of tax-transfers conforms to

$$
N_{t}^{y} \tau_{t}=N_{t}^{o} b_{t-1} \Longrightarrow n_{t-1} \tau_{t}=b_{t-1}
$$

for $t \geq 1$. For now, we set aside the SS system and focus solely on a FC.

\subsection{The agent's problem}

At date $t$, an agent in her youth chooses $c_{t}$ and $n_{t}$, as well as a consumption plan, $x_{t}$. The agent also decides whether or not to participate in her FC. Given a $\left(\alpha_{t}, \alpha_{t+1}\right) \in \mathfrak{R}_{++}^{2}$, her problem is:

$$
\max u\left(c_{t}\right)+\beta u\left(x_{t}\right)+\theta g\left(n_{t}\right)
$$

\footnotetext{
${ }^{10}$ Since, by design, agents are not altruistic towards their children, they make no gifts or transfers to them. Cigno (2006 a) additionally allows for gifts from parents to children. In his setup, an altruistic parent may choose to pass on a generous gift to her children when they are young and accept a smaller transfer from them when they become adults. The latter imperative may weaken the threat of generational autarky that keeps the FC alive and viable.
} 
subject to

c1 $c_{t}+\alpha_{t}+v n_{t} \leq w$

c2 $x_{t} \leq y+\alpha_{t+1} n_{t}$

c3 $c_{t} \geq 0 ; x_{t} \geq 0 ; n_{t} \geq 0$.

When (c1) and (c2) bind, the choice variable satisfies:

$$
v u^{\prime}\left(w-\alpha_{t}-v n_{t}\right)=\theta g^{\prime}\left(n_{t}\right)+\alpha_{t+1} \beta u^{\prime}\left(y+\alpha_{t+1} n_{t}\right) .
$$

Eq. (2) implicitly defines a solution, $n_{t}=n\left(\alpha_{t} ; \alpha_{t+1}\right)$ which, using (c1) and (c2), define indirect utility $\left(U_{t}\right)$ the agent obtains under the FC.

As will be explained below, if the agent chooses not to abide by the FC, her choice of $n_{t}$ satisfies

$$
v u^{\prime}\left(w-v n_{t}\right)=\theta g^{\prime}\left(n_{t}\right) .
$$

Under this option - her outside option - she receives $\underline{U}_{t} \equiv u\left(w-v \underline{n}_{t}\right)+\beta u(y)+\theta g\left(\underline{n}_{t}\right)$, where $\underline{n}_{t}$ satisfies (3). In this case, $c_{t}=w-v \underline{n}_{t}$ and $x_{t}=y$. If $\theta=0$, then $\underline{n}_{t}=0$ (because raising children is costly) and the agent simply consumes his endowment. In that case, $\underline{U}_{t}=\underline{U} \equiv u(w)+\beta u(y)$. The importance of assuming $y>0$ is apparent here; since $u^{\prime}(0) \rightarrow \infty$, allowing $y=0$ precludes non-existence of the FC simply because the outside option is so unappealing. Also note if $\theta=0$, no one has children outside of the FC and the economy ends.

We proceed to derive a family compact. The existence or non-existence of a FC relies solely on the view that children are investment goods. Whether they are also viewed as consumption goods is totally immaterial to the survial of a FC. To keep the discussion simple, until further notice, we set $\theta=0$.

\subsection{The family compact}

So far, we have loosely described a family compact as a sequence of transfers, $\left\{\alpha_{t}\right\}_{t=1}^{\infty}$, whose viability requires that, at each date, the utility obtained under it, $U_{t}$, is at least as great as that from 
the outside option, $\underline{U}_{t}$. This characterization is not entirely complete, since a family member at any generation can take an action, call it $\widehat{\alpha}_{t}$, that differs from $\alpha_{t}$. As such, the compact must also describe the actions of all current and future agents if such deviations do occur at some date. While important, these represent the 'fine print' of the compact. ${ }^{11}$ Since they are secondary to our main focus, we relegate them to an appendix.

We now turn to the notion of viability. When $\theta=0$, a sequence $\left\{\alpha_{t}\right\}_{t=1}^{\infty}$ of transfers is viable (self-enforcing in the language of Cigno, 2006a) - the FC is subgame perfect - if

$$
V\left(\alpha_{t} ; \alpha_{t+1}\right)=u\left(w-v n\left(\alpha_{t} ; \alpha_{t+1}\right)-\alpha_{t}\right)+\beta u\left(y+\alpha_{t+1} n\left(\alpha_{t} ; \alpha_{t+1}\right)\right) \geq \underline{U},
$$

holds for each date $t$, where $n\left(\alpha_{t} ; \alpha_{t+1}\right)$ is, mutatis mutandis, the solution to (2). A family compact is not unique. There may be a continuum of sequences $\left\{\alpha_{t}\right\}_{t=1}^{\infty}$ that satisfy (4).

Needless to say, a FC must also ensure each generation procreates, i.e., $n\left(\alpha_{t} ; \alpha_{t+1}\right)>0 \forall t$. Let $A$ denote the set of $\left(\alpha_{t}, \alpha_{t+1}\right)$ consistent with $n\left(\alpha_{t} ; \alpha_{t+1}\right) \geq 0$. For each transfer $\alpha_{t}$ an agent is asked to give to her parent, there is a minimum transfer $\alpha_{\min , t+1} \geq 0$ she must anticipate receiving before she is willing to have children, i.e., $n\left(\alpha_{t} ; \alpha_{\min , t+1}\right)=0$ for all $\alpha_{t} \geq 0$. The smallest of these is defined implicitly by $n\left(0 ; \alpha_{\min }\right)=0$. More generally, the locus of $\alpha_{\min , t+1}-$ call it the mapping $\gamma\left(\alpha_{t}\right)$ - is increasing in $\alpha_{t}$. Any feasible $\alpha_{t+1}>\gamma\left(\alpha_{t}\right)$ is consistent with procreation at date $t$.

Next, consider the function $\phi\left(\alpha_{t}\right):(0, w) \longrightarrow\left(\alpha_{\min }, w\right)$, defined implicitly as $V\left(\alpha_{t} ; \phi\left(\alpha_{t}\right)\right)=$ $\underline{U}$, i.e., given $\alpha_{t}, \phi(\cdot)$ describes the size of the anticipated transfer from the young to old at $t+1$ that leaves the young at $t$ just as well off as the benchmark, $\underline{U}$. It follows that $V(0 ; \phi(0))=$ $V\left(0 ; \alpha_{\min }\right)=\underline{U}$. The mapping $\phi\left(\alpha_{t}\right) \geq \gamma\left(\alpha_{t}\right)$ for all $\alpha_{t} \geq 0$. Figure 1 illustrates, with a

\footnotetext{
${ }^{11} \mathrm{~A}$ 'private social security system' requires trust; there must exist rewards and punishments for such a system of trust to operate. Kandori (1992) and Salant (1991) have shown that in overlapping generations models there can be outcomes, which support such cooperative arrangements even though the identity of players is changing over time.
} 
blue curve, a convex mapping $\phi\left(\alpha_{t}\right) .{ }^{12,13}$ Any transfer combination above the blue line generates higher utility than the outside option.Let $\underline{\alpha}(\bar{\alpha})$ denote the smallest (largest) fixed point $\alpha=\phi(\alpha)$ with $\alpha<w$.

Proposition 1 Let $\alpha_{1}^{*} \in(0, \bar{\alpha}]$ be any initial transfer. A subgame perfect sequence of transfers consistent with procreation, $\left\{\alpha_{t}^{*}\right\}_{t=1}^{\infty}$, if it exists, satisfies i) $\alpha_{t+1}^{*} \geq \phi\left(\alpha_{t}^{*}\right) \geq \gamma\left(\alpha_{t}^{*}\right)$ and ii) $\alpha_{t}^{*} \in$ $(0, \bar{\alpha}]$.

Henceforth, we restrict attention to sequences that satisfy the proposition.

Consider next, a stationary equilibrium, i.e., $\alpha_{t}=\alpha>0$ for $t \geq 1$. It is clear that stationary equilibria belong to the set $[\underline{\alpha}, \bar{\alpha}]$. These are shown as points along the yellow line in Figure 1 .

\footnotetext{
${ }^{12}$ Why might $\phi\left(\alpha_{t}\right)$ be convex? Differentiating $V\left(\alpha_{t} ; \phi\left(\alpha_{t}\right)\right)=\underline{U}$ and using the envelope theorem, we obtain $\phi^{\prime}\left(\alpha_{t}\right)=\frac{1}{n_{t}} \frac{u^{\prime}\left(c_{t}\right)}{\beta u^{\prime}\left(x_{t}\right)}>0$, which, using (2) with $\theta=0$, and $n_{t}=n\left(\alpha_{t} ; \alpha_{t+1}\right)$, yields $\phi^{\prime}\left(\alpha_{t}\right)=\frac{1}{v} \frac{\alpha_{t+1}}{n\left(\alpha_{t} ; \alpha_{t+1}\right)}$. The second derivative is

$$
\phi^{\prime \prime}\left(\alpha_{t}\right)=\frac{\alpha_{t+1}}{v n^{2}}\left[\frac{1}{v}\left(1-\frac{\alpha_{t+1}}{n} \frac{\partial n\left(\alpha_{t} ; \alpha_{t+1}\right)}{\partial \alpha_{t+1}}\right)-\frac{\partial n\left(\alpha_{t} ; \alpha_{t+1}\right)}{\partial \alpha_{t}}\right] .
$$

The sign here is inconclusive; it is easy to show $\frac{\partial n\left(\alpha_{t} ; \alpha_{t+1}\right)}{\partial \alpha_{t}}<0$ but the sign of $\frac{\partial n\left(\alpha_{t} ; \alpha_{t+1}\right)}{\partial \alpha_{t+1}}$ and the term including the elasticity, $\left(1-\frac{\alpha_{t+1}}{n} \frac{\partial n\left(\alpha_{t} ; \alpha_{t+1}\right)}{\partial \alpha_{t+1}}\right)$, are ambiguous. If the elasticity is negative or smaller than unity, $\phi^{\prime \prime}\left(\alpha_{t}\right)>0$ over the domain of $\alpha_{t}$ and the function $\phi(\cdot)$ is strictly convex.

${ }^{13}$ In drawing Figure 1, we have assumed, implicitly, $\phi^{\prime}(0)<1$ and $\lim _{\alpha \rightarrow w} \phi^{\prime}(\alpha)>1$, which are necessary (but not sufficient) for the existence of fixed point of $\phi(\cdot)$ if the function is strictly convex. Also note, the mapping $\phi(\cdot)$ may not exist - its existence rests critically on the utility function, the endowment profile, the per-child cost of raising children, $\nu$, and the discount factor $\beta$. Loosely (and not surprisingly), a mapping exists when the old-age endowment $(y)$ is sufficently small compared to $w$.
} 


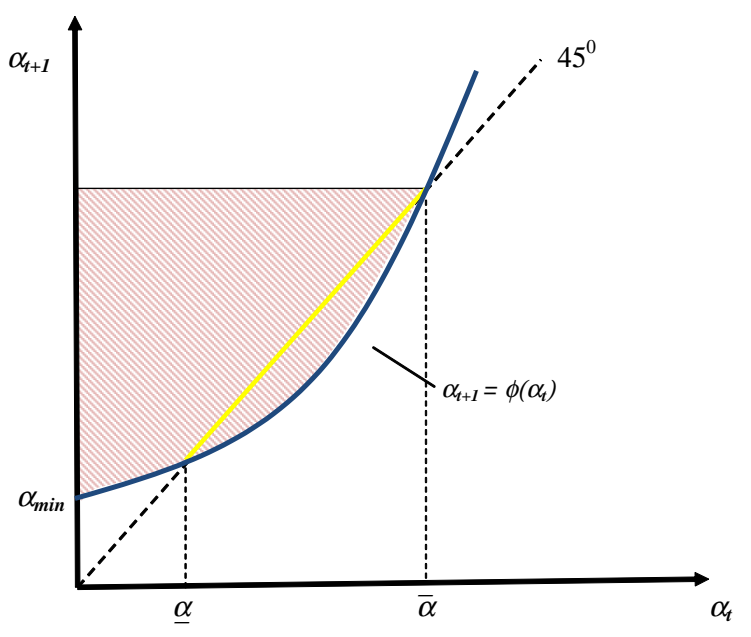

Figure 1: The set of subgame perfect transfers.

Setting aside the welfare of the initial transfer recipients (the old at date $t=1$ ), the best such compact, is the one that maximizes the distance between the blue curve (no-compact alternative) and yellow line (stationary compacts) - where $\phi^{\prime}(\alpha)=1$, and solves the following problem: choose $\alpha$ to maximize

$$
\widehat{V}(\alpha) \equiv u(w-v n(\alpha ; \alpha)-\alpha)+\beta u(y+\alpha n(\alpha ; \alpha))
$$

Using the envelope theorem, and assuming an interior solution for $\alpha$, the first-order condition reduces to

$$
-u^{\prime}(w-v n-\alpha)+n \beta u^{\prime}(y+\alpha n)=0,
$$

which can be rewritten as $u^{\prime}(c) / \beta u^{\prime}(x)=n$. Combine (7) with (2) above to get

$$
n=\frac{\alpha}{v}
$$


In sum, the best stationary private subgame perfect compact is jointly given by (8) - the number of children - and the size of the transfer, implicitly defined by

$$
-u^{\prime}(w-2 \alpha)+\frac{\alpha}{v} \beta u^{\prime}\left(y+\frac{\alpha^{2}}{v}\right)=0
$$

following (7). In his specific context, Cigno (2006a) defines this set - (8) and (9) - to be the set of "renegotiation-proof" family constitutions in a stationary setting. In the appendix, we work out an example - with $u(c)=\ln c$ and $\theta=0$ - wherein we prove that the aforediscussed optimal, stationary compact (consistent with procreation) exists.

It bears to emphasize the decision to abide by the FC or not is endogenous. Since there is no heterogeneity among the children, they will all abide by the FC or none of them will. And, in the steady state, if the parent has the incentive to pass along the transfer, the children will as well. By construction - see (4) - there is no risk of default; either the FC is viable or it is not. Given the lack of uncertainty in family transfers within a FC, there can be no efficiency-enhancing, insurance role for public SS vis-a-vis the FC.

\section{Pensions: Public and Private}

Up to this point, we have discussed the workings of a family compact in a setting where children are viewed solely as investment goods. In such a setting, there is no point to procreation - the economy stops - in the absence of a family compact. This possibility is easily prevented by allowing parents to, additionally, treat children as consumption goods. It also allows us to study a publicly-sponsored pension system in which the youth of today pay taxes to support pensions for the current old.

\subsection{Introducing a public pension}

Consider an arbitrary, stationary, public pension system, $\tau_{t}=\tau, \forall t$ satisfying (1). Assume such a system is introduced alongside an existing, stationary, private family compact. The agent's problem is given by:

$\max u\left(c_{t}\right)+\beta u\left(x_{t}\right)+\theta g\left(n_{t}\right)$ 
subject to

$$
\begin{aligned}
& c_{t}+\alpha_{t}+v n_{t}+\tau \leq w \\
& x_{t} \leq y+\alpha_{t+1} n_{t}+b \\
& c_{t} \geq 0 ; x_{t} \geq 0 ; n_{t} \geq 0 .
\end{aligned}
$$

Plugging the constraints into the objective function we get the following first order condition for $n$ in a stationary situation for given $\alpha, \tau$ and $b$ :

$$
v u^{\prime}(w-\alpha-v n-\tau)=\theta g^{\prime}(n)+\alpha \beta u^{\prime}(y+\alpha n+b) .
$$

The second order condition is given by $D \equiv v^{2} u^{\prime \prime}+\beta \alpha^{2} u^{\prime \prime}+\theta g^{\prime \prime}<0$. It is easy to check that

$$
\frac{\partial n}{\partial \tau}=\frac{-v u^{\prime \prime}}{D}<0
$$

Incorporating the government budget constraint, $b=\tau n$, the stationary interior analogs of (2) and (7) are written as

$$
v u^{\prime}(w-\alpha-v n-\tau)=\theta g^{\prime}(n)+\alpha \beta u^{\prime}(y+\alpha n+\tau n),
$$

and

$$
u^{\prime}(w-v n-\alpha-\tau)=n \beta u^{\prime}(y+\alpha n+\tau n) .
$$

The stationary compact, $\alpha$, must also satisfy $u(w-v n-\alpha-\tau)+\beta u(y+\alpha n+\tau n)+\theta g(n) \geq$ $u(w-v \underline{n}-\tau)+\beta u(y+\tau \underline{n})+\theta g(\underline{n})$ where $\underline{n}$ satisfies $v u^{\prime}(w-v \underline{n}-\tau)=\theta g^{\prime}(\underline{n}) .{ }^{14}$ Here again, note if $\theta=0$, no one has children outside of the FC and the economy ends; as such, if $\theta=0$, and FCs are not viable, a public SS system cannot emerge. In other words, if we are to study the possible emergence of a public SS in a world where FCs have ceased to be viable, we have to impose $\theta>0$.

The question we explore in this section is, can introducing a stationary public system alongside an existing, stationary, private family compact improve steady-state welfare? We find

\footnotetext{
${ }^{14}$ Once again, note that given $u^{\prime}(0)=\infty$, if $y=0$ and $\tau=0$, a viable stationary compact will always survive since there is no other means to acquire the consumption good.
} 
Proposition 2 Introducing (or increasing the scope of) a public pension system along side a stationary private family compact cannot increase the welfare of agents in a steady state.

Proof. To see this, note the steady-state indirect utility of an agent under such a joint pension system is given by

$$
V(\tau) \equiv u(w-v n(\tau)-\alpha(\tau)-\tau)+\beta u(y+\alpha(\tau) n(\tau)+\tau n(\tau))+\theta g(n(\tau))
$$

where the functions $n(\tau)$ and $\alpha(\tau)$ represent the solutions for $n$ and $\alpha$ satisfy (11) and (12), for

given $\tau$. Differentiating (13), we can glean the effect on an agent's welfare from a marginal increase in $\tau$ :

$$
\begin{gathered}
V^{\prime}(\tau)=u^{\prime}(c)\left(-v n^{\prime}(\tau)-\alpha^{\prime}(\tau)-1\right)+\beta u^{\prime}(x)\left(\alpha^{\prime}(\tau) n(\tau)+\alpha(\tau) n^{\prime}(\tau)+n(\tau)+\tau n^{\prime}(\tau)\right) \\
+\theta g^{\prime}(n(\tau)) n^{\prime}(\tau)=\beta \tau n^{\prime}(\tau) u^{\prime}(x)
\end{gathered}
$$

here, in deriving the second equality in (14), we have used the envelope theorem - (11) and (12). From (10), $n^{\prime}(\tau) \leq 0$ which proves $V^{\prime}(\tau) \leq 0$.

Heuristically, a FC lines up the intertemporal tradeoff in a desirable way; there is nothing left for the SS tax to 'correct'. The underlying problem is that private agents view the public tax-transfer scheme as lump sum and fail to internalize the budgetary implications of their fertility decision (which the government takes as given). The government's tax is seen only as an imposition with no salient counterpart; moreover, they fail to understand the connection between the pension they are promised and the number of kids they have. As such, the tax reduces available young-age income, and as a result, agents reduce their fertility, i.e., $n^{\prime}(\tau) \leq 0$.

\subsection{When do compacts break down?}

The above proposition makes clear that a public pension system cannot offer agents anything more than what they can achieve on their own through an optimally-selected family compact. Therefore, a benevolent government has no welfare justification for introducing SS in a world with activelythriving family compacts. The upshot is that both a private family compact and a public SS system 
cannot coexist. That said, a natural question to ask is, when might such private compacts break down?

A casual look at the changing nature of the public's attitude toward private versus public pension systems suggests that a catalyst for change may be large and persistent shocks to income. Indeed, social pension initiatives were enacted as part of larger, social welfare reforms during severe economic declines (for example, Germany, 1880s and the United States, 1930s). Here, we take up two parts of this argument. First, in Proposition 3, we show that within the context of the model with no public pensions, an optimal stationary family compact may fail to obtain, precisely because of low income $(w)$ when young. ${ }^{15}$ A way to think about this result, in a broader context, is to envision a stationary equilibrium with a family compact in place. At some date, say, $T$, there is a large, unexpected (and perceived permanent) decrease in $w$. At that point, the young at $T$ are unable to make good on the existing family compact - and, based on the perceived longevity of the shock, a new family compact cannot be initiated. From that point onward, the economy would revert to a no-compact benchmark world, until a future shock or change in government policy alters the equilibrium. Second, given the inability to support a new stationary equilibrium with a family compact, it is natural to inquire if an optimal stationary public pension system can be initiated to replace the now-defunct private one. Unfortunately, the condition that ensures the non-existence of a stationary family compact - low-enough $w$ - also precludes the existence of an optimal stationary public system, as shown in Proposition 4.

Proposition 3 Assume a stationary family compact exists for a given endowment profile $(w, y)$. Suppose there is an unexpected, permanent negative shock to $w$. If the shock is large enough: i) the existing family compact will fall apart, and ii) a new stationary family compact, with a smaller, positive transfer to the old, does not attain.

Proof. The original family compact is assumed to satisfy:

$$
-u^{\prime}(w-v n-\alpha)+n \beta u^{\prime}(y+\alpha n) \leq 0
$$

\footnotetext{
${ }^{15}$ For simplicity, we assume no change in old-age endowment, $y$. Conditions for non-existence can be suitably modified to incorporate changes in the entire income profile $(w, y)$.
} 


$$
v u^{\prime}(w-v n-\alpha)=\theta g^{\prime}(n)+\alpha \beta u^{\prime}(y+\alpha n)
$$

A stationary family compact will not attain, if, for every transfer $\alpha>0$, (15) holds with a strict inequality for any $n$ that satisfies (16). Given this, we begin by looking at the mappings $u^{\prime}(w-v n), \theta / v g^{\prime}(n)$ - these are depicted as the upward (downward) sloped thick curves in Figure 2 - and the mapping $n \beta u^{\prime}(y)$, the line emanating from the origin in Figure 2. At the point $n=n(0), n \beta u^{\prime}(y)=\theta / v g^{\prime}(n)$. With $n(0)$ in hand, define $\hat{w}$ as the value of $w$ such that $u^{\prime}(\hat{w}-v n(0))=n(0) \beta u^{\prime}(y)$. Such a value for $w$ exists, for any given $n(0)$, if $u^{\prime}(\cdot)$ satisfies the usual limit conditions, i.e., $\lim _{c \rightarrow 0} u^{\prime}(\cdot)=\infty, \lim _{c \rightarrow \infty} u^{\prime}(\cdot)=0$. By construction, both (15) and (16) hold with equality at $n=n(0)$ and $w=\hat{w}$, as shown in Figure 2 .

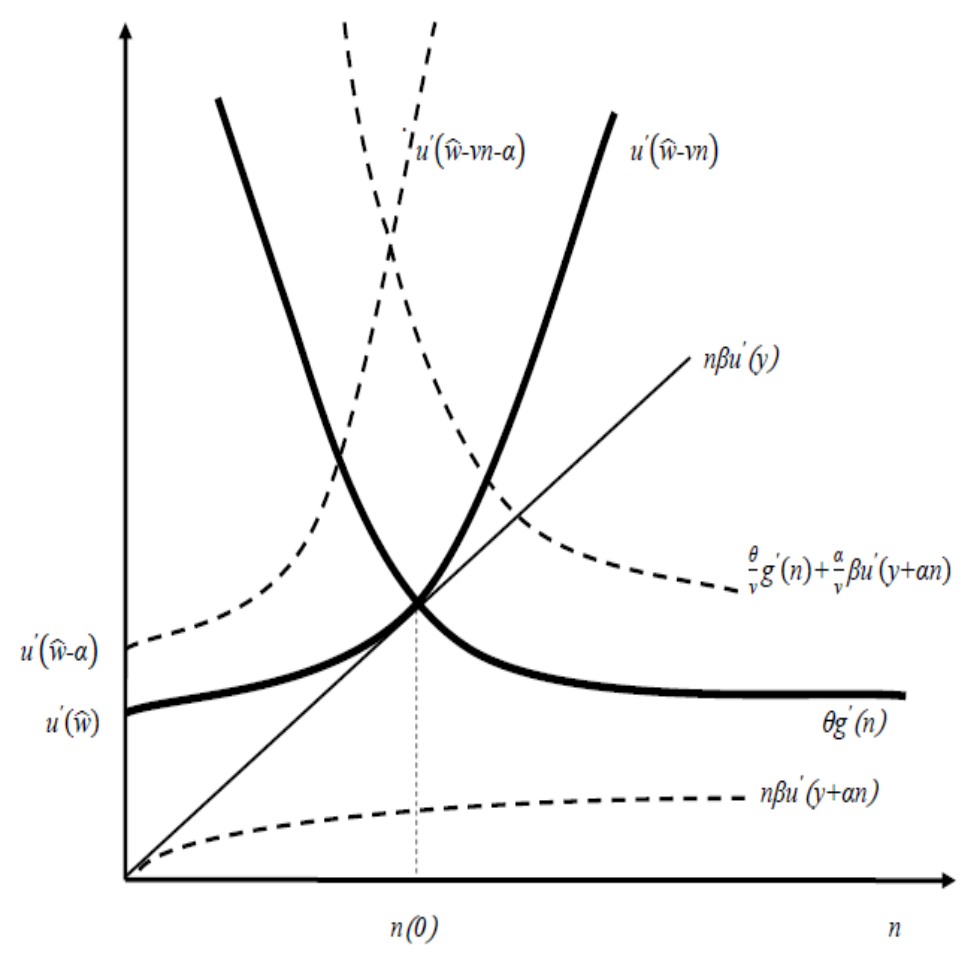

Figure 2: Eqns. (15) and (16)

To understand how a system of family compacts can break down entirely, suppose there is an unexpected and permanent change in the first period endowment, $w$; specifically, holding $y$ fixed, 
suppose the new first period endowment satisfies $w \leq \hat{w}$. With $w=\hat{w}$, any transfer $\alpha>0$ from young to old shifts the curves shown in Figure 2 in such a way that (15) holds with a strict inequality, meaning the optimal compact is $\alpha=0$, since the cost of the transfer, in utility terms, exceeds the benefit. These are shown in Figure 2 (the dotted curves show how the original curves shift for any $\alpha>0)$. Any endowment strictly less than $\hat{w}$ shifts the curve $u^{\prime}(w-v n-\alpha)$ further up, ensuring no stationary compact exists.

We turn next to the public pension system. We enquire if an optimal stationary public pension system can be initiated to replace the destroyed private compact. To that end, set $\alpha(\tau) \equiv 0$ in (14) above; then, the optimal public pension satisfies

$$
-u^{\prime}(c)+\beta n(\tau) u^{\prime}(x)+\beta \tau u^{\prime}(x) n^{\prime}(\tau) \leq 0
$$

where $n$ satisfies

$$
v u^{\prime}(w-v n-\tau)=\theta g^{\prime}(n)
$$

Note that in writing (18), we have used the fact that the future pension transfer is public, and therefore, taken as given by the agent when deciding on fertility. In short, under a public system, children are no longer investment goods.

Clearly, by construction, when $w=\hat{w}$, the compact breaks down and hence, it follows from $(15)-u^{\prime}(c)+\beta n(\tau) u^{\prime}(x)<0$. Since $n^{\prime}(\tau) \leq 0,(17)$ holds with strict inequality for any $\tau>0$ whenever $w<\hat{w}$, similar to the case with private pensions, as shown in Figure 2. Therefore, optimal $\tau=0$. Formally,

Proposition 4 Suppose $w \leq \hat{w}$. Then an optimal public pension system with $\tau>0$ does not attain.

Essentially, when $w$ falls to $\hat{w}$, a young agent can no longer make transfers to her parent and have any remaining resources to consume and raise children of her own. At that point, the young agent abandons the investment-utility benefit of the compact in favor of the direct consumptionutility of having children. 
Summarizing, we have shown that a publicly-funded pension system does not provide additional support if an optimal private family compact is in place - indeed, introducing such a system can even lower welfare in the steady state. While a family compact can perform well, it may break down in the presence of large, permanent shocks to agents' incomes. While this may seem to provide an ideal time for the introduction of a publicly-funded pension system, we find the conditions that prevent families from starting a new, albeit less-generous family compact, also prevents an optimal, steady-state public pension system from starting up.

\subsection{Discussion}

It deserves emphasis that our version of the optimal public pension problem takes per-capita steady state lifetime utility as the objective function of the government. This choice is deliberate, and made for two reasons. First, a public pension program that uses steady-state lifetime utility as its objective function most closely mirrors the best of the family compacts, since the latter, devoid of any altruistic ties across generations, ignores intergenerational trade-offs. Secondly - and perhaps more fundamentally - a dynamic planning problem may not be well posed. To see this, imagine a planner at the initial date that puts a 'weight' of $\kappa$ on the initial old generation and $(1-\kappa)$ on the weighted sum of the lifetime utility of all future generations, where each successive generation of middle-age decisionmakers has a 'weight' of $0<\lambda^{t-1}<1$, for $t \geq 1$. The objective function for such a planner is given by

$$
\Omega=\kappa N_{1}^{o} u\left(x_{0}\right)+(1-\kappa) \sum_{t=0}^{\infty} \lambda^{t} N_{t+1}^{y} V_{t+1}
$$

where $V_{t}$ represents the lifetime utility of a middle-aged decision maker at date $t$. There is no assurance, however, that the sum on the right hand side of (19) is finite, since the population growth rate is endogenous and dependent on the choices of the planner; nor can the same be said of the family compact equivalent to this sum, with which we'd like to make a comparison. ${ }^{16}$

\footnotetext{
${ }^{16}$ Specifically, there is no way to ensure $\lambda n<1$ for any of the three alternatives (autarky, family compact, and the public pension system).
} 
As an alternative, one can conceive of an objective function made up of a weighted sum of per capita utility across generations,

$$
\hat{\mathbf{\Omega}}=\kappa u\left(x_{0}\right)+(1-\kappa) \sum_{t=0}^{\infty} \lambda^{t} V_{t+1}
$$

Since the allocations we study here are stationary, we have

$$
\hat{\Omega}^{i}=\kappa u\left(x_{0}\right)+(1-\kappa) \frac{V_{1}^{i}}{1-\lambda}
$$

where $i$ indexes the alternative (autarky (a), family compact $(f)$, or publicly funded SS $(s)$ ). Our analysis in Section 3.1 is conducted for the special case of $\kappa=0 .{ }^{17}$

Finally, a numerical example comparing the alternatives.

Example 1 Let $g(a)=u(a)=\frac{a^{1-\sigma}}{1-\sigma}$ for $a=c, x, n$, and $w=10 ; y=2 ; \beta=0.6 ; \theta=1 ; v=2$ and $\sigma=0.96$ The consumption allocations $c, x$, number of children, $n$, family compact $\alpha$ or social security tax $\tau$, and steady-state per capita utility for autarky and optimal family compact and publicly-funded SS systems are presented in Table $1 .{ }^{18}$

\begin{tabular}{|c|c|c|c|c|c|c|c|}
\hline Alternative & $c$ & $n$ & $x$ & $\alpha$ & $\tau$ & $V$ & $\hat{\Omega}$ \\
\hline Family Compact $(f)$ & 3.62 & 2.49 & 5.49 & 1.40 & - & 68.31 & 98.51 \\
\hline SS $(s)$ & 4.40 & 2.14 & 4.82 & - & 1.32 & 68.27 & 98.46 \\
\hline Autarky $(a)$ & 5.07 & 2.46 & 2 & - & - & 68.02 & 97.87 \\
\hline
\end{tabular}

As evident in this example, the population growth under an SS system is lower than under a family compact or autarky. Fewer children and a lower intergenerational transfer ( $\tau$ versus $\alpha$ ) allow for greater consumption when young under the SS system. Of course, this comes at the expense of lower consumption when old. The family compact, as noted, provides greater steady state per capita utility.

\footnotetext{
${ }^{17}$ Setting $\kappa=0$ is also consistent with our focus exclusively on the pension performance of the two systems. When $\kappa \neq 0$, the planner attaches some weight to the utility of those that do not contribute to the pension system (the initial old) and hence places some value on the redistributive aspects of the program.

${ }^{18}$ The last column of Table 1 presents the value for $\hat{\Omega}^{i}$, assuming the planner discounts the future in the same manner as agents, i.e., $\lambda=\beta$, with $\kappa=1 / 2$. We also assume the size of the intital old generation is the same as that of the intial young.
} 


\section{Conclusion}

In this paper we examine the workings of a family pension system, one where children provide support for their elders in exchange for future pension care from their offspring. This system resembles institutions in place prior to the emergence of support for the elderly through publicly funded social security reforms in the late 19th and early 20th centuries. Our results suggest that, in the confines of the model we study, these family compacts work fairly well: they preclude the introduction of publicly-funded pay-as-you-go social security. If one looks only at the pension aspect of social security, to the total exclusion of its other vaunted benefits, one finds that private family compacts did just as well on that front. Moreover, if a large income shock dislodged the family compacts, no benevolent government would wish to set up a social security program in their place. Our work suggests that the pension role of social security could not have been its raison d'être.

At first blush, it may appear that one reason for the introduction of a public pension system, apart from its redistributive role, may be a need for insurance. For example, there may be an exogenous family dissolution, say, due to migration, that leads to nullification of existing compacts. The compact we have considered ignore such a possibility; however, since they satisfy subgame perfection, there is no endogenous reason for default on the compacts. If young-age income uncertainty is an issue, family compacts can easily be rewritten to accommodate this concern. The tenor of our results, mutatis mutandis, would still be maintained.

One component not present in the current discussion is mortality. The possibility of a child's death before reaching adulthood creates additional cost for both a family compact and a governmentsponsored social security scheme. Within a family compact, this cost is internalized; one can treat it analogous to a decrease in the return to children as an investment good. In a world in which oldage security is provided solely through SS, and agents view children only as consumption goods, the possibility that a child may die before reaching adulthood has no direct impact on agents' fertility decisions; indirectly, however, it will affect the size of the available pool of young agents from which to tap for contributions to the system, and, hence, the size of the SS transfer to each old 
agent. The mortality of agents from mid-age to old has much different ramifications. In a world with only family compacts, the premature death of a parent frees her children from the obligation of the transfer stipulated under the compact. In such a setting, those whose parents died early will choose to have more children than those whose parents survived, thereby creating an endogenous distribution of fertility. By contrast, under a pure SS system, there is no difference in fertility across agents since fertility is no longer tied to a family transfer obligation. Moreover, the public system can exploit the fact that some young agents will contribute into the program but not be around to receive any benefits. Precisely how mortality figures into the comparison of these two systems is an avenue for further study. And yet, it seems mortality is hardly the hook on which to establish the continued primacy of SS systems. 


\section{Appendix}

\section{A The compact's fine print}

Perhaps an efficient way to characterize this compact is to make the distinction between obligations, $\alpha_{t}$, actions, $\widehat{\alpha}_{t}$, and contingent obligations $\widetilde{\alpha}_{t}$, of which the latter can be thought of as a description of how a child, in accordance with the compact, should respond to the actions of a parent. Define a history of the family obligations as a list of the amount of obligatory donations up to the date $t$, $t \geq 2$ as $H^{t} \equiv\left(\alpha_{1}, \alpha_{2}, \ldots, \alpha_{t-1}\right)$, and likewise, for actions $\widehat{H}^{t}$ and contingent obligations $\widetilde{H}^{t}$.

We envision the matriarch of this family compact, the young decisionmaker at date 1, proposing a sequence of family transfer obligations for all future generations $\left\{\alpha_{t}\right\}_{t=2}^{\infty}$, as well as a donational transfer to her own parents, $\alpha_{1}>0$ at date 1 . The compact also lays out how individuals should act (contingent obligations $\left\{\widetilde{\alpha}_{t}\right\}_{t=2}^{\infty}$. Trivially, we set $\alpha_{1}=\widehat{\alpha}_{1}=\widetilde{\alpha}_{1}$.

At date 2 , the young decisionmaker faces obligation $\alpha_{2}$ and contingent obligation $\widetilde{\alpha}_{2}$, which, in this case, since $\alpha_{1}=\widehat{\alpha}_{1}=\widetilde{\alpha}_{1}, \widetilde{\alpha}_{2}$ is equal to $\alpha_{2}$. In other words, since her parent at date 1 selected action $\widehat{\alpha}_{1}=\widetilde{\alpha}_{1}$, the minimum transfer she needs to make at date 2 to be in compliance with the compact is the obligation $\alpha_{2} .{ }^{19}$ At this time, she chooses an action $\widehat{\alpha}_{2}$ (this choice is described in detail further below), which may or may not be in compliance with the compact.

The compact at this stage becomes more descriptive. The young decisionmaker at date 2 is obliged to pass along a transfer $\widetilde{\alpha}_{2}=\alpha_{2}$. At date 3, the parent's child knows whether the parent's action $\widehat{\alpha}_{2}$ lived up to the compact or not. Therefore, the contingent obligation facing this child, at date 3 , is

$$
\widetilde{\alpha}_{3}=\left\{\begin{array}{cc}
\alpha_{3} & \text { if } \widehat{\alpha}_{2}=\widetilde{\alpha}_{2} \\
0 & \text { otherwise }
\end{array} .\right.
$$

More generally, given $H^{t}, \widetilde{H}^{t}$ and $\widehat{H}^{t}$, for $t \geq 2$, a contingent obligation facing a young agent at date $t$ consists of a transfer plan $\widetilde{\alpha}_{t}$, with

$$
\widetilde{\alpha}_{t}=\left\{\begin{array}{cc}
\alpha_{t} & \text { if } \widehat{\alpha}_{t-1}=\widetilde{\alpha}_{t-1} \\
0 & \text { otherwise }
\end{array} .\right.
$$

Since these contingent plans are defined recursively, it is useful to express them in terms of actions and obligations, as well as updated one period:

\footnotetext{
${ }^{19}$ Technically, an agent can pass along a transfer $\widehat{\alpha}_{t}$ to her parent that is greater than her familial obligation $\alpha_{t}$, but in this model with no altruistic tie running from child to parent, there is no incentive for her to give any more than $\alpha_{t}$. In writing out the contingent obligations $\tilde{\alpha}_{t}$ below, it makes it easier
} 


$$
\widetilde{\alpha}_{t+1}=\left\{\begin{array}{ccc}
\alpha_{t+1} & \text { if } \widehat{\alpha}_{t}=\alpha_{t} & \text { (A) } \\
\alpha_{t+1} & \text { if } \widehat{\alpha}_{t}=0 \text { and } \widehat{\alpha}_{t-1} \neq \widetilde{\alpha}_{t-1} & \text { (B) } \\
0 & \text { otherwise } & \text { (C) }
\end{array} .\right.
$$

Note that in this form, an offspring of a young decisionmaker at date $t$ is obliged to follow the compact provided her parent passes along a sufficient transfer to her parent at date $t$ (A). The compact also stipulates that the child, at $t+1$, is obliged to pass on $\alpha_{t+1}$ in the event that her parent, in fulfilling her compact compact commitments, does not leave a transfer to her parent (the child's grandparent) at $t$ in the event that the grandparent failed to carry out the contingent obligation to her parent (the child's great grandparent) at $t-1$ (B) Any transfer action $\widehat{\alpha}_{t}$ not meeting the conditions laid out in (A) or (B) of 24 constitutes a failure to live up to the compact at date $t$ and confirms onto the child the obligation to pass along a 0 transfer at $t+1$.

The force of these contingency plans (and especially, B) ensures that if the child follows the compact and punishes the parent for noncompliance of the compact at date $t$, the child will not face a withholding of a transfer from her child at $t+2$. Another way to put this is that she is assured the transfer $\alpha_{t+2}>0$ even if she withholds a transfer from the wayward parent at $t+1$ (and, by (C), she is assured punishment at $t+2$ if she fails to punish her wayward parent at $t+1$ ). Together, these contingency plans ensure the threat of punishment is credible - the parent's child has the incentive to mete out a punishment at date $t+1$ if the parent fails to live up to her contingent obligation at $t$ - provided the compact obligations $\alpha_{t+1}, \alpha_{t+2}$ offer the child something better than what she can do on her own (which we assume they do - see below). Any deviation by one generation simply results in a response by the next that reverts back to the original compact plan.

\section{B An example with logarithmic preferences}

Let $u(c)=\ln c$ and $\beta w>2 \sqrt{(1+2 \beta) v y}$. For this example, an interior solution for the number of children, $n,(2$ above $)$ satisfies

$$
\frac{v}{w-\alpha_{t}-v n_{t}}=\frac{\beta \alpha_{t+1}}{y+\alpha_{t+1} n_{t}}
$$

which implies a solution

$$
n\left(\alpha_{t} ; \alpha_{t+1}\right)=\frac{\beta \alpha_{t+1} w-\beta \alpha_{t} \alpha_{t+1}-v y}{\alpha_{t+1} v(1+\beta)} .
$$

Here, $\alpha_{\min }=v y / \beta w$, and, for a given $\alpha_{t}$, the set $\left\{\alpha_{t+1}: \alpha_{t+1} \geq \frac{\alpha_{\min } w}{w-\alpha_{t}}\right\}$ defines the set of permissible future transfers that ensure $n\left(\alpha_{t} ; \alpha_{t+1}\right) \geq 0$. (For any $\alpha_{t+1}$ not in this set, the solution to the agent's problem at date $t$ is $\left.n_{t}=0\right)$. 
With $\alpha_{t}=\alpha_{t+1}=\alpha$ for all $t, n$ is increasing in $\alpha$, for $\alpha<\sqrt{y v / \beta}$ and decreasing thereafter. The set of stationary compacts which ensure $n(\alpha ; \alpha) \geq 0$, $A=\left\{\alpha: \frac{1}{2 \beta}\left(w \beta-\sqrt{w^{2} \beta^{2}-4 y \beta v}\right)<\alpha<\frac{1}{2 \beta}\left(w \beta+\sqrt{w^{2} \beta^{2}-4 y \beta v}\right)\right\}$.

An agent's utility under a compact is:

$$
\begin{aligned}
V\left(\alpha_{t} ; \alpha_{t+1}\right) & =\ln \left(w-v \frac{\beta \alpha_{t+1} w-\beta \alpha_{t} \alpha_{t+1}-v y}{\alpha_{t+1} v(1+\beta)}-\alpha_{t}\right)+\beta \ln \left(y+\alpha_{t+1} \frac{\beta \alpha_{t+1} w-\beta \alpha_{t} \alpha_{t+1}-v y}{\alpha_{t+1} v(1+\beta)}\right) \\
& =(1+\beta) \ln \left(\alpha_{t+1}\left(w-\alpha_{t}\right)+y v\right)-\ln \alpha_{t+1}+C,
\end{aligned}
$$

where $C \equiv \beta \ln \beta-(1+\beta) \ln (1+\beta)-\beta \ln v$, is a constant. The expression for lifetime utility, $V\left(\alpha_{t} ; \alpha_{t+1}\right)$, is valid for all pairs $\left(\alpha_{t} ; \alpha_{t+1}\right), \alpha_{t}, \alpha_{t+1} \leq w$, with $n\left(\alpha_{t} ; \alpha_{t+1}\right) \geq 0$. In particular, when $\alpha_{t}=\alpha_{t+1}=\alpha, V(\alpha)$ is defined for all $\alpha \in A$. (Note that in this case, the expression, $w-v n(\alpha ; \alpha)-\alpha$, which represents first period consumption, equals $\frac{\left(w \alpha-\alpha^{2}+y v\right)}{\alpha(1+\beta)}$; this term is positive for all compacts $0<\alpha<w)$. We have

$$
V(\alpha)=(1+\beta) \ln \left(w \alpha+y v-\alpha^{2}\right)-\ln \alpha+C .
$$

The limit of lifetime utility $V(\alpha)$ as $\alpha$ approaches the lower bound of $A, \underline{\alpha}_{A}$ is $\ln \left(w-\underline{\alpha}_{A}\right)+\beta \ln y$, and at its upper bound, $\bar{\alpha}_{A}$, is $\ln \left(w-\bar{\alpha}_{A}\right)+\beta \ln y$; both are less than the benchmark (no-compact) alternative $\ln w+\beta \ln y$. As we indicated above, the set $A^{\prime}$ of transfers that equal or beat the benchmark alternative is contained in $A$.

For a given $\alpha_{t}$, the mapping $\phi\left(\alpha_{t}\right)$ is defined implicitly in the following manner:

$$
(1+\beta) \ln \left(\phi\left(\alpha_{t}\right)\left(w-\alpha_{t}\right)+y v\right)-\ln \phi\left(\alpha_{t}\right)+C=\ln w+\beta \ln y,
$$

and the points $\underline{\alpha}$ and $\bar{\alpha}$ satisfy

$$
\begin{aligned}
& (1+\beta) \ln (\underline{\alpha}(w-\underline{\alpha})+y v)-\ln \underline{\alpha}+C=\ln w+\beta \ln y \\
& (1+\beta) \ln (\bar{\alpha}(w-\bar{\alpha})+y v)-\ln \bar{\alpha}+C=\ln w+\beta \ln y .
\end{aligned}
$$

The set of stationary compacts $A^{\prime} \equiv\{\alpha: \underline{\alpha} \leq \alpha \leq \bar{\alpha}\}$.

Above, we showed that the optimal stationary compact satisfies the condition, $n=\frac{\alpha}{v}$. Using the expression $n(\alpha ; \alpha)$, we can solve directly for $\alpha .{ }^{20}$

$$
\alpha=\frac{w \beta \pm \sqrt{w^{2} \beta^{2}-4 y v-8 \beta y v}}{4 \beta+2} .
$$

Call these two roots $\alpha^{-}$and $\alpha^{+}$. The assumption $\beta w>2 \sqrt{(1+2 \beta) v y}$ ensures the solutions (27) are real valued.

\footnotetext{
${ }^{20}$ Of course, alternatively, we can compute the optimal compact by differentiating lifetime utility $V(\alpha)(26)$ with respect to $\alpha$.
} 
How can we be assured that lifetime utility $V(\alpha)$ under one of these solutions exceeds the benchmark $u(w)+\beta u(y)$ ? First, note that

$$
V^{\prime}(\alpha)=-\frac{y v+\alpha^{2}+2 \alpha^{2} \beta-w \alpha \beta}{\alpha(\alpha(w-\alpha)+v y)}
$$

which is negative for low $\alpha$, and, in particular, for $\alpha<\alpha^{-}$. Second, we note that at the boundaries of the set of permissible stationary compacts with $n \geq 0$, we have $V\left(\bar{\alpha}_{A}\right)<V\left(\underline{\alpha}_{A}\right)<u(w)+$ $\beta u(y)$. Finally, we show $\underline{\alpha}_{A}<\alpha^{-}<\alpha^{+}<\bar{\alpha}_{A}$ :

$$
\begin{aligned}
& \bar{\alpha}_{A}-\alpha^{+}=\frac{1}{2 \beta}\left(w \beta+\sqrt{w^{2} \beta^{2}-4 y \beta v}\right)-\frac{w \beta+\sqrt{w^{2} \beta^{2}-4 y v-8 \beta y v}}{4 \beta+2} \\
& =\frac{1}{2 \beta(2 \beta+1)}\left(w \beta-\beta \sqrt{w^{2} \beta^{2}-8 y v \beta-4 y v}+2 \beta \sqrt{w^{2} \beta^{2}-4 y \beta v}+w \beta^{2}+\sqrt{w^{2} \beta^{2}-4 y \beta v}\right)>0,
\end{aligned}
$$

since $w \beta-\beta \sqrt{w^{2} \beta^{2}-8 y v \beta-4 y v}>w \beta-\beta \sqrt{w^{2} \beta^{2}}=w \beta(1-\beta)>0$.

Similarly,

$$
\begin{aligned}
& \alpha^{-}-\underline{\alpha}_{A}=\frac{w \beta-\sqrt{w^{2} \beta^{2}-4 y v-8 \beta y v}}{4 \beta+2}-\frac{1}{2 \beta}\left(w \beta-\sqrt{w^{2} \beta^{2}-4 y \beta v}\right) \\
& =\frac{1}{2 \beta(2 \beta+1)}\left((2 \beta+1) \sqrt{w^{2} \beta^{2}-4 y \beta v}-\beta \sqrt{w^{2} \beta^{2}-8 y v \beta-4 y v}-w \beta(1+\beta)\right)
\end{aligned}
$$

This latter expression is decreasing in $y$. Using the assumption $\beta w>2 \sqrt{(1+2 \beta) v y} \Rightarrow \frac{(\beta w)^{2}}{4(1+2 \beta) v}>$ $y$, we evaluate at $y=\frac{(\beta w)^{2}}{4(1+2 \beta) v}$ :

$$
\begin{aligned}
& \alpha^{-}-\underline{\alpha}_{A}>\frac{w \beta}{2 \beta(2 \beta+1)}\left((2 \beta+1) \sqrt{\frac{1+\beta}{2 \beta+1}}-(1+\beta)\right) \\
& =\frac{w \beta}{2 \beta(2 \beta+1)}(\sqrt{2 \beta+1} \sqrt{1+\beta}-(1+\beta)) \\
& >\frac{w \beta}{2 \beta(2 \beta+1)}(\sqrt{1+\beta} \sqrt{1+\beta}-(1+\beta))=0
\end{aligned}
$$

The stationary compact and the optimal compact, $\alpha^{+}$are depicted below in the figure below: 


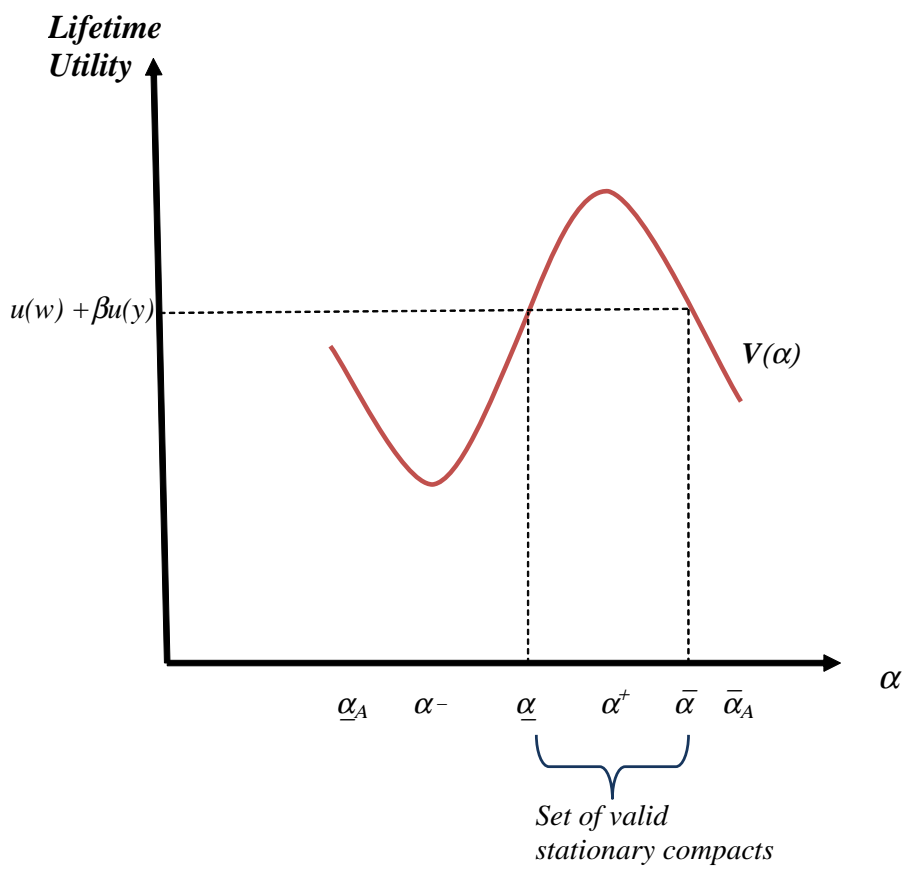

Figure 3: Lifetime utility $V(\alpha)$ and the no-compact benchmark. 


\section{References}

[1] Atchley, R.C. (1982): "Retirement as a Social Institution, Annual Review of Sociology 8, 263-287.

[2] Barro, R.J. and G. S. Becker (1989): Fertility Choice in a Model of Economic Growth, Econometrica 57, 481-501.

[3] Becker, G.S. and R.J. Barro (1988): A Reformulation of the Economic Theory of Fertility, Quarterly Journal of Economics CIII, 1-25.

[4] Boldrin, M. and L. Jones (2002): Mortality, Fertility and Saving in a Malthusian Economy, Review of Economic Dynamics 5, 775-814.

[5] Boldrin, M., De Nardi, M., and L. Jones (2005): Fertility and Social Security, Research Department Staff Report 359, Federal Reserve Bank of Minneapolis.

[6] Cigno, A. (1993): Intergenerational transfers without altruism. Family, market and state, European Journal of Political Economy 9, 505-518.

[7] Cigno, A. (2006a): A constitutional theory of the family, Journal of Population Economics 19, 259-283.

[8] Cigno, A. (2006b): The political economy of intergenerational cooperation, Chapter 25 In: Serge-Christophe Kolm and Jean Mercier Ythier, Editor(s), Handbook on the Economics of Giving, Reciprocity and Altruism, Elsevier, Volume 2, Pages 1505-1558.

[9] Ehrlich, I. and J. Kim (2005): Social security and demographic trends: Theory and evidence from the international experience, Review of Economic Dynamics 10, 55-77.

[10] Fenge, R. and Volker Meier (2005) "Pensions and Fertility Incentives", Canadian Journal of Economics 38(1), 28-48

[11] Galasso, V. Gatti, R. and Profeta, P. (2009) "Investing for the old age: Pensions, children and savings", International Tax and Public Finance 16(4): 538-559.

[12] Galasso, V. and Profeta, P. (2010) "When the State Mirrors the Family: The Design of Pension Systems", CESIFO WORKING PAPER NO. 3191

[13] Galor, O. and D.N. Weil (1996): The Gender Gap, Fertility and Growth, American Economic Review 86, 374-387.

[14] Kandori, M. (1992): Repeated Games Played by Overlapping Generations of Players, Review of Economic Studies 59, 81-92. 
[15] Mulligan, C. B. and Sala-i-Martin, X. (2004): Political and Economic Forces Sustaining Social Security, Advances in Economic Analysis \& Policy: 4(1), Article 5.

[16] Nishimura, K and Zhang, J. (1992) Pay-as-you-go Public Pensions with Endogenous Fertility, Journal of Public Economics, 239-58.

[17] Rosati, F.C. (1996): Social security in non-altruistic model with uncertainty and endogenous fertility. Journal of Public Economics 60, 283-294.

[18] Salant, D. (1991): A Repeated Game with Finitely Lived Overlapping Generations of Players, Games and Economic Behavior 3, 244-259.

[19] Tanzi, V.; and Schuknecht, L. (2000) Public Spending in the 20th Century. Cambridge University Press.

[20] Zhang, J. and Zhang, J. (1998) "Social Security, Intergenerational Transfers, and Endogenous Growth", Canadian Journal of Economics 31(5), 1225-1241

[21] Zhang, J., and Zhang, J., (2007). Optimal social security in a dynastic model with investment externalities and endogenous fertility. Journal of Economic Dynamics and Control 31, 33453567.

[22] Yew, S. L. and Zhang, J. (2009) "Optimal social security in a dynastic model with human capital externalities, fertility and endogenous growth",Journal of Public Economics, 93, 605619 